\title{
A Tool to Predict the Probability of Intracerebral Recurrence or New Cerebral Metastases After Whole-brain Irradiation in Patients with Head-and-Neck Cancer
}

\author{
CHRISTIAN STAACKMANN $^{1}$, STEFAN JANSSEN ${ }^{1,2},{\text { STEVEN E. } \text { SCHILD }^{3} \text { and DIRK RADES }}^{1}$ \\ ${ }^{1}$ Department of Radiation Oncology, University of Lübeck, Lübeck, Germany; \\ ${ }^{2}$ Private Practice of Radiation Oncology, Hannover, Germany; \\ ${ }^{3}$ Department of Radiation Oncology, Mayo Clinic, Scottsdale, AZ, U.S.A.
}

\begin{abstract}
Background/Aim: Patients with metastatic headand-neck cancer require individual therapies facilitated by prognostic tools. A tool to estimate the risk of recurrent or new cerebral metastases following whole-brain irradiation (WBI) is presented. Patients and Methods: Age, gender, performance status, cancer site, number of cerebral lesions, extracerebral metastases, and time between cancer diagnosis and treatment of cerebral metastases were evaluated for intracerebral control in 23 patients. For characteristics showing a trend $(p<0.07)$, points for these characteristics were created by dividing 6-month intracerebral control rates by 10. Patient scores were obtained by adding these points. Results: Better intracerebral control was significantly associated with oropharyngeal and laryngeal cancer $(p=0.014)$. Absence of extra-cerebral metastases $(p=0.069)$ and longer time between cancer diagnosis and treatment of cerebral metastases $(p=0.053)$ showed trends. Three groups were identified, namely with 3-11, 13-18 and 20-24 points. Six-month intracerebral control rates were 0\%, 50\% and $100 \%$ ( $p=0.003)$, respectively, for these groups. Conclusion: A new tool was created to predict intracerebral control following WBI and should contribute to personalization of treatment for patients with cerebral metastases of head-andneck cancer.
\end{abstract}

Patients with cerebral metastases from head-and-neck cancer generally have poor prognoses (1). Many systemic anticancer drugs pass through the blood-brain barrier poorly and are not

Correspondence to: Dirk Rades, MD, Department of Radiation Oncology, University of Lübeck, Lübeck, Ratzeburger Allee 160, 23562 Lübeck, Germany. Tel: +49 45150045401, Fax: +49 45150045404, e-mail: Rades.Dirk@gmx.net

Key Words: Cerebral metastases, whole-brain irradiation, intracerebral recurrence, head-and-neck cancer, predictive tool. as effective for brain metastases (2-4). Thus, radiotherapy is the most common treatment modality for cerebral metastases from head-and-neck cancer. Radiotherapy options include local techniques, such as radiosurgery and fractionated stereotactic radiotherapy (5). However, local techniques are reasonable in patients with a limited number of cerebral lesions (5-8). Therefore, the most frequently administered type of radiotherapy in patients with metastases from headand-neck cancer is whole-brain irradiation (WBI) (5). WBI may be combined with local radiotherapy or upfront neurosurgical resection in selected cases, particularly in patients with very few lesions $(9,10)$. For WBI, a variety of dose-fractionation regimens are in use worldwide, also depending on national preferences and standards (5). Usually these regimens are administered with one fraction per day and five fractions per week. They include shorter programs that take one week (e.g. $5 \times 4 \mathrm{~Gy})$ and longer programs that take up to four weeks $($ e.g. $10 \times 3 \mathrm{~Gy}$ and $20 \times 2 \mathrm{~Gy})(11,12)$. When aiming to select for the optimal WBI program for an individual patient, many factors should be considered, including the patient's social situation, distance to the Radiation Oncology Department, personal treatment preferences, and the patient's remaining lifespan. A prognostic score to estimate the survival prognosis of patients irradiated for cerebral metastases from head-andneck cancer is already available (13). Previous studies suggested that patients with a very limited prognosis are better candidates for a less time-consuming shorter WBI program, whereas those with a very favorable survival prognosis can benefit from longer programs with lower doses per fraction, in terms of better survival and fewer neurocognitive deficits $(11,14-16)$. However, the appropriate regimen for patients with an intermediate survival prognosis is often unclear. For these patients, another aspect becomes more important, namely the ability of WBI to provide longterm intracerebral control, i.e. freedom from new and progression of treated cerebral metastases. The biologically- 
effective dose, which can be given as equivalent dose in 2-Gy-fractions (EQD2), of a WBI program depends on both total dose and dose per fraction (17). In general, longer WBI programs are associated with higher EQD2. For example, the EQD2 of $5 \times 4 \mathrm{~Gy}, 10 \times 3$ Gy and $20 \times 2$ Gy are $23.3 \mathrm{~Gy}$, $32.5 \mathrm{~Gy}$ and $40.0 \mathrm{~Gy}$, respectively. In radiation oncology, a higher EQD2 generally means a greater efficacy with respect to tumor cell kill and local (intracerebral) control, which has been described for the treatment of primary head-and-neck cancer and for cerebral metastases from other solid tumors (18-23). However, a higher EQD2 often also means a higher risk of radiation-related toxicities. Prior to radiotherapy, it would be advantageous to identify those patients with cerebral metastases from head-and-neck cancer and an intermediate survival prognosis who may benefit from WBI with a higher EQD2 with respect to long-term intracerebral control. The present study aimed to provide a prognostic tool to do so by predicting the risk of developing recurrent or new cerebral metastases following WBI in patients with cerebral metastases from head-and-neck cancer.

\section{Patients and Methods}

Twenty-three patients who had received WBI alone ( $n=19)$, WBI with upfront resection or WBI with boost with upfront resection for cerebral metastases from head-and-neck cancer between 1995 and 2015 were included in this retrospective study. Dose-fractionation of WBI regimens included $5 \times 4$ Gy in 1 week $(n=4), 10 \times 3$ Gy in 2 weeks $(n=11)$ and longer-course regimens with doses $>30$ Gy given over 3-4 weeks $(n=8)$. Seven pre-treatment characteristics were evaluated with respect to intracerebral control. Intracerebral control was defined as lack of progression of treated lesions and freedom from new cerebral metastases. These characteristics included age ( $\leq 64$ vs. $\geq 65$ years, median age: 65 years), gender, Eastern Cooperative Oncology Group (ECOG) performance score (0-1 vs. 2-3, median performance score: 2), site of origin of head-and-neck cancer (nasopharynx vs. oropharynx vs. larynx $v s$. other sites), number of cerebral lesions (1-2 vs. $\geq 3$, median: 3 lesions), extracerebral metastases (no $v s$. yes) and time between diagnosis of headand-neck cancer and treatment of cerebral metastases ( $\leq 24 \mathrm{vs} .>24$ months, median time: 24 months). Distributions of the characteristics are shown in Table I. For statistical analyses, the Kaplan-Meier method and log-rank test were used (24). Those characteristics that showed significance $(p<0.05)$ or a trend $(p<0.07)$ with respect to intracerebral control were used to design the prognostic tool. For each of these characteristics, a separate score was created by dividing the 6-month intracerebral control rate (as a percentage) by 10 . The prognostic score for each patient was then obtained by summing the scores for each characteristic.

\section{Results}

Better intracerebral control was significantly associated with oropharyngeal and laryngeal cancer $(p=0.014)$. In addition, absence of extra-cerebral metastases $(p=0.069)$ and longer time (i.e. $>24$ months) between diagnosis of head-and-neck cancer and treatment of cerebral metastases $(p=0.053)$
Table I. Distribution of patient characteristics.

\begin{tabular}{lc}
\hline & Number of patients $(\%)$ \\
\hline Age at the time of treament & \\
$\leq 64$ Years & $11(48)$ \\
$\geq 65$ Years & $12(52)$ \\
Gender & \\
Female & $5(22)$ \\
Male & $18(78)$ \\
ECOG performance score & \\
$0-1$ & $11(48)$ \\
$2-3$ & $12(52)$ \\
Site of primary tumor & \\
Nasopharynx & $2(9)$ \\
Oropharynx & $5(22)$ \\
Larynx & $8(35)$ \\
Other & $8(35)$ \\
Number of cerebral lesions & \\
$1-2$ & $10(43)$ \\
$\geq 3$ & $13(57)$ \\
Extracerebral metastases & \\
No & $11(48)$ \\
Yes & $12(52)$ \\
Time between cancer diagnosis and & \\
treatment of cerebral metastases & \\
$\leq 24$ Months & \\
$>24$ Months & $12(52)$ \\
\hline
\end{tabular}

WBI: Whole-brain irradiation, ECOG: Eastern Cooperative Oncology Group.

showed trends for better intracerebral control (Table II). These three characteristics were used to design the prognostic tool to estimate the 6-month probability of intracerebral control, as described in the Patients and Methods section (Table III). The prognostic scores for individual patients ranged between 3 and 24 points and were $3,7,10,11,13,14$, $15,17,18,20,22$ or 24 points, respectively. Based on these scores, three prognostic groups were formed, namely 3-11 points, 13-18 points and 20-24 points. The 6-month intracerebral control rates were $0 \%$ (median control of 4 months), 50\% (median control of 9.5 months) and 100\% (median control not reached), respectively $(p=0.003)$.

\section{Discussion}

The primary treatment of locally advanced head-and-neck cancer can be improved due to modern radiotherapeutic approaches and combination with chemotherapy and immunotherapy (25-27). Therefore, more patients live longer, which generally translates into an increased risk of experiencing metastatic disease correlating with a patient's lifespan. Patients presenting with cerebral metastases of headand-neck cancer are still rare and account for only about $1 \%$ of patients with metastatic disease affecting the brain (1). 
Table II. Intracerebral control rates 6 months following whole-brain irradiation.

\begin{tabular}{|c|c|c|}
\hline & $\begin{array}{l}\text { Intracerebral control } \\
\text { at } 6 \text { months }(\%)\end{array}$ & $p$-Value \\
\hline \multicolumn{3}{|c|}{ Age at time of treament } \\
\hline$\leq 64$ Years & 53 & \\
\hline$\geq 65$ Years & 48 & 0.676 \\
\hline \multicolumn{3}{|l|}{ Gender } \\
\hline Female & 56 & \\
\hline Male & 51 & 0.796 \\
\hline \multicolumn{3}{|c|}{ ECOG performance score } \\
\hline $0-1$ & 69 & \\
\hline $2-3$ & 26 & 0.093 \\
\hline \multicolumn{3}{|c|}{ Site of primary tumor } \\
\hline Nasopharynx & 0 & \\
\hline Oropharynx & 100 & \\
\hline Larynx & 80 & \\
\hline Other & 0 & 0.014 \\
\hline \multicolumn{3}{|c|}{ Number of cerebral lesions } \\
\hline $1-2$ & 45 & \\
\hline$\geq 3$ & 67 & 0.878 \\
\hline \multicolumn{3}{|c|}{ Extracerebral metastases } \\
\hline No & 74 & \\
\hline Yes & 0 & 0.069 \\
\hline \multicolumn{3}{|c|}{$\begin{array}{l}\text { Time between cancer diagnosis and } \\
\text { treatment of cerebral metastases }\end{array}$} \\
\hline$\leq 24$ months & 29 & \\
\hline$>24$ months & 67 & 0.053 \\
\hline
\end{tabular}

WBI: Whole-brain irradiation, ECOG: Eastern Cooperative Oncology Group. Significant $p$-values are shown in bold type.

The prognoses of these patients require improvement that may be achieved with individualized treatment approaches. For patients assigned to receiving WBI for their cerebral metastases, individualization would include the selection of the appropriate dose-fractionation schedule. In a previous study, an instrument was presented that can help predict the survival times of individual patients with cerebral metastases from head-and-neck cancer (13). That scoring instrument was based on performance status, and number of cerebral lesions and extracranial metastases, and included three prognostic groups with 6-month survival rates of $0 \%$ (0-1 point), $50 \%$ ( 2 points) and $100 \%$ (3 points). In a larger retrospective study of 442 patients with cerebral metastases from different solid tumors and mainly poor survival prognoses, $5 \times 4 \mathrm{~Gy}$ in 1 week was not inferior to $10 \times 3$ Gy in 2 weeks regarding intracerebral control $(p=0.07)$, survival $(p=0.29)$ and acute toxicity; $5 \times 4$ Gy was recommended particularly for patients with a poor survival prognosis (11). This would apply to the $0-1$ point group by the survival score previously created for patients with cerebral metastases form head-and-neck cancer (13). On the other hand, patients with a very favorable survival prognosis were reported to benefit from longer-course WBI programs with lower doses
Table III. Points assigned for the characteristics included in the prognostic tool derived by dividing the percentage 6-month intracerebral control rate by 10 .

\begin{tabular}{lcr}
\hline Characteristic & $\begin{array}{c}\text { Intracerebral control } \\
\text { at } 6 \text { months (\%) }\end{array}$ & Points \\
\hline Site of primary tumor & 0 & \\
$\quad$ Nasopharynx & 100 & 0 \\
$\quad$ Oropharynx & 80 & 8 \\
$\quad$ Larynx & 0 & 0 \\
$\quad$ Other & 74 & \\
Extra-cerebral metastases & 0 & 7 \\
$\quad$ No & & 0 \\
$\quad$ Yes & & \\
Time between cancer diagnosis and & 29 & 3 \\
treatment of cerebral metastases & 67 & 7 \\
$\quad \leq 24$ Months & & \\
$>24$ Months & & \\
\hline
\end{tabular}

per fraction in terms of improved intracerebral control and survival with fewer neurocognitive deficits (14-16). Therefore, patients of the group with 3 points by the previously created survival score would appear to be good candidates for a longercourse WBI program (13). However, for patients of the intermediate group (2 points) by that survival score, the optimal WBI program is more difficult to select. To make an appropriate treatment decision, additional information would be required including the risk of an intracerebral failure.

Therefore, in the present study, an additional prognostic tool was developed that allows estimation of the intracerebral control rates at 6 months following WBI. Based on three pretreatment characteristics, namely site of origin of head-andneck cancer, extracerebral metastases and time between diagnosis of head-and-neck cancer and treatment of cerebral metastases, three groups were identified with significantly different 6-month intracerebral control probabilities. These rates were $0 \%$ for $3-11$ points, $50 \%$ for $13-18$ points and $100 \%$ for 20-24 points, respectively. Because a higher dose of WBI can be expected to result in more efficient tumor-cell kill, patients of the group with 3-11 points and the 13-18 points with an intermediate survival prognosis may benefit from longer-course WBI programs with a higher EQD2 in order to achieve a better 6-month intracerebral control. In conclusion, a new tool was created that can help predict the intracerebral control probability 6 months following WBI and can, therefore, contribute to the personalization of the treatment for patients with cerebral metastases from head-and-neck cancer.

\section{Conflicts of Interest}

On behalf of all Authors, the corresponding Author states that there is no conflict of interest related to this study. 


\section{References}

1 Siegel RL, Miller KD and Jemal A: Cancer statistics, 2017. CA Cancer J Clin 67: 7-30, 2017.

2 Cooper JB, Ronecker JS, Tobias ME, Mohan AL, Hillard V, Murali R, Gandhi CD, Schmidt MH and Jhanwar-Uniyal M: Molecular sequence of events and signaling pathways in cerebral metastases. Anticancer Res 38: 1859-1877, 2018.

3 Erdő F, Nagy I, Tóth B, Bui A, Molnár É, Tímár Z, Magnan R and Krajcsi P: ABCB1A (P-glycoprotein) limits brain exposure of the anticancer drug candidate seliciclib in vivo in adult mice. Brain Res Bull 132: 232-236, 2017.

4 Lockman PR, Mittapalli RK, Taskar KS, Rudraraju V, Gril B, Bohn KA, Adkins CE, Roberts A, Thorsheim HR, Gaasch JA, Huang S, Palmieri D, Steeg PS and Smith QR: Heterogeneous blood-tumor barrier permeability determines drug efficacy in experimental brain metastases of breast cancer. Clin Cancer Res 16: 5664-5678, 2010.

5 Tsao MN, Rades D, Wirth A, Lo SS, Danielson BL, Gaspar LE, Sperduto PW, Vogelbaum MA, Radawski JD, Wang JZ, Gillin MT, Mohideen N, Hahn CA and Chang EL: Radiotherapeutic and surgical management for newly diagnosed brain metastasis(es): An American Society for Radiation Oncology evidence-based guideline. Pract Radiat Oncol 2: 210-225, 2012.

6 Rades D, Hornung D, Veninga T, Schild SE and Gliemroth J: Single brain metastasis: Radiosurgery alone compared with radiosurgery plus up-front whole-brain radiotherapy. Cancer 118: 2980-2985, 2012.

7 Rades D, Huttenlocher S, Hornung D, Blanck O and Schild SE: Radiosurgery alone versus radiosurgery plus whole-brain irradiation for very few cerebral metastases from lung cancer. BMC Cancer 14: 931, 2014.

8 Rades D, Janssen S, Dziggel L, Blanck O, Bajrovic A, Veninga $\mathrm{T}$ and Schild SE: A matched-pair study comparing whole-brain irradiation alone to radiosurgery or fractionated stereotactic radiotherapy alone in patients irradiated for up to three brain metastases. BMC Cancer 17: 30, 2017.

9 Rades D, Kueter JD, Veninga T, Gliemroth J and Schild SE: Whole brain radiotherapy plus stereotactic radiosurgery (WBRT+SRS) versus surgery plus whole brain radiotherapy (OP+WBRT) for 1-3 brain metastases: Results of a matched pair analysis. Eur J Cancer 45: 400-404, 2009.

10 Rades D, Veninga T, Hornung D, Wittkugel O, Schild SE and Gliemroth J: Single brain metastasis: whole-brain irradiation plus either radiosurgery or neurosurgical resection. Cancer 118 : 1138-1144, 2012.

11 Rades D, Kieckebusch S, Lohynska R, Veninga T, Stalpers LJ, Dunst $J$ and Schild SE: Reduction of overall treatment time in patients irradiated for more than three brain metastases. Int J Radiat Oncol Biol Phys 69: 1509-1513, 2007.

12 Rades D, Haatanen T, Schild SE and Dunst J: Dose escalation beyond 30 Grays in 10 fractions for patients with multiple brain metastases. Cancer 110: 1345-1350, 2007.

13 Rades D, Dziggel L, Hakim SG, Rudat V, Janssen S, Trang NT, Khoa MT and Bartscht T: Predicting survival after irradiation for brain metastases from head and neck cancer. In Vivo 29: 525$528,2015$.

14 DeAngelis LM, Delattre JY and Posner JB: Radiation-induced dementia in patients cured of brain metastases. Neurology 39: 789-796, 1989.
15 Shaw MG and Ball DL: Treatment of brain metastases in lung cancer: Strategies to avoid/reduce late complications of whole brain radiation therapy. Curr Treat Options Oncol 14: 553-567, 2013.

16 Rades D, Panzner A, Dziggel L, Haatanen T, Lohynska R and Schild SE: Dose-escalation of whole-brain radiotherapy for brain metastasis in patients with a favorable survival prognosis, Cancer 118: 3853-3859, 2012.

17 Joiner MC and Van der Kogel AJ: The linear-quadratic approach to fractionation and calculation of isoeffect relationships. In: Basic Clinical Radiobiology. Steel GG (ed.). New York, Oxford University Press, pp. 106-112, 1997.

18 Seidl D, Janssen S, Strojan P, Hakim SG, Wollenberg B, Schild $\mathrm{SE}$ and Rades $\mathrm{D}$ : Importance of chemotherapy and radiation dose after microscopically incomplete resection of stage III/IV head and neck cancer. Anticancer Res 36: 2487-2491, 2016.

19 Rades D, Janssen S, Bajrovic A, Strojan P and Schild SE: A total radiation dose of $70 \mathrm{~Gy}$ is required after macroscopically incomplete resection of squamous cell carcinoma of the head and neck. Anticancer Res 36: 2989-2992, 2016.

20 Rades D, Hornung D, Blanck O, Martens K, Khoa MT, Trang NT, Hüppe M, Terheyden P, Gliemroth J and Schild SE: Stereotactic radiosurgery for newly diagnosed brain metastases: comparison of three dose levels. Strahlenther Onkol 190: 786-791, 2014.

21 Rades D, Huttenlocher S, Dahlke M, Hornung D, Blanck O, Thai PV, Trang NT, Khoa MT and Schild SE: Comparison of two dose levels of stereotactic radiosurgery for 1-3 brain metastases from non-small cell lung cancer. Anticancer Res 34: 7309-7313, 2014.

22 Rades D, Huttenlocher S, Rudat V, Hornung D, Blanck O, Phuong PC, Khoa MT, Schild SE and Fischer D: Radiosurgery with 20 Gy provides better local contol of 1-3 brain metastases from breast cancer than with lower doses. Anticancer Res 35: 333-336, 2015.

23 Heisterkamp C, Haatanen T, Schild SE and Rades D: Dose escalation in patients receiving whole-brain radiotherapy for brain metastases from colorectal cancer. Strahlenther Onkol 186: 70-75, 2010.

24 Kaplan EL and Meier P: Non-parametric estimation from incomplete observations. J Am Stat Assoc 53: 457-481, 1958.

25 Seidl D, Janssen S, Strojan P, Bajrovic A, Schild SE and Rades D: Prognostic factors after definitive radio(chemo)therapy of locally advanced head and neck cancer. Anticancer Res 36: 2523-2526, 2016.

26 Bonner JA, Harari PM, Giralt J, Cohen RB, Jones CU, Sur RK, Raben D, Baselga J, Spencer SA, Zhu J, Youssoufian H, Rowinsky EK and Ang KK: Radiotherapy plus cetuximab for locoregionally advanced head and neck cancer: 5-year survival data from a phase 3 randomised trial, and relation between cetuximab-induced rash and survival. Lancet Oncol 11: 21-28, 2010.

27 Bonomo P, Desideri I, Loi M, Mangoni M, Sottili M, Marrazzo L, Talamonti C, Greto D, Pallotta S and Livi L: Anti PD-L1 durvalumab combined with cetuximab and radiotherapy in locally advanced squamous cell carcinoma of the head and neck: A phase I/II study (DUCRO). Clin Trans1 Radiat Oncol 9: 42-47, 2018.

Received May 8, 2018

Revised May 28, 2018

Accepted May 29, 2018 